\title{
AN EVALUATION OF MANET PROTOCOLS IN TERMS OF TCP VARIANTS BASED ON THIER PERFORMANCES USING OPNETT
}

\author{
Satinder Singh Minhas ${ }^{1}$, Pooja Chaudhary ${ }^{2}$, Vikrant Sharma ${ }^{3}$, Jaspreet Kaur ${ }^{4}$ \\ ${ }^{1}$ Lecturer, Electronics and Communication Engineering, Lovely Professional University, Punjab, India \\ ${ }^{2}$ Assistant Professor, Information and Technology, CT Institute of Engineering Management \& Technology, Punjab, \\ India \\ ${ }^{3}$ Vice-Principal, Electronics and Communication Engineering, CT Institute of Technology, Punjab, India \\ ${ }^{4}$ Lecturer, Electronics and Communication Engineering, Lovely Professional University, Punjab, India
}

\begin{abstract}
MANET stands for Mobile Ad-Hoc network which means an on-demand network with $n$ number of mobile nodes, each connected to one another through wireless connections. These networks has many advantages over the traditional wireless networks such as ease of setting up, no need for infrastructure etc. Due to the presence of mobility in the MANET, the interconnections between stations are likely to change on a continual basis, resulting in frequent changes of network topology. The transport control protocol (TCP) is responsible for providing reliable data transport in the Internet. As a matter of fact, it is extensively tuned to providing high-quality performance in the conventional wired network. However, it cannot offer reliable service while using e-mail, internet search, several application file transmission in a mobile Ad-hoc network. Several studies reveal that TCP does not perform as well in a mobile environment as it does in other networks. There are several factors that affect the TCP performance in MANETs, such as dynamic topology, shared medium, signal fading and high bit errors. , there are other factors like network size, network load, bandwidth and signal strength that affect the performance of the MANET routing protocols. Therefore, a detailed analysis is required in order to gain an insight of these factors that determine the performance of the routing protocol. So in this paper we will be discoursing different aspects of the network design. The measurements were taken in the light of throughput, end to end delay etc using DSR and AODV protocols of MANET. Simulation is done in Optimized Network Engineering Tool14.5 (OPNET 14.5).
\end{abstract}

Keywords: MANET, TCP Variants, different routing protocols, OPNET.

\section{INTRODUCTION}

MANET is a self-configuring network of mobile routers (and associated hosts) connected by wireless links. It forms a random topology in which each node works as a router and move randomly free in the area. Setting up of fixed access point and backbone infrastructure is not always possible for example infrastructure may not be present in a disaster area or war zone or infrastructure may not be practical for short range radios. So in such scenarios MANET is the most useful tool that can be used as they do not need infrastructure support and easy to deploy. Due to changes in topology of MANET the interconnections between the nodes are likely to be changed on continual basis resulting in hindrance in communication and throughput. So routing becomes a vital factor and a major challenge in such networks. In this paper we will consider two routing protocols optimized Link state routing (OLSR) and Ad-Hoc On demand distance network (AODV). In addition from a transport layer's perspective it is consider Transmission Control Protocol (TCP) as well for MANET because of its wide application. So in this paper we will be presenting the results based on parameters i.e throughput and end-to-end delay after evaluating the performance of MANET's existing protocols in terms of TCP variants (Reno and New Reno).

\section{SIMULATION TOOL USED}

The evaluation is conducted using discrete event simulation software known as OPNET Modeler. In order to evaluate the whole process the most recently available version OPNET 14.5 is used. The OPNET is one of the most extensively used commercial simulators based on Microsoft windows platform, which incorporates most of the MANET routing parameters compared to other simulators. It also incorporates a number of features to support an increase in stability and mobility in the mobile ad-hoc network.

\subsection{Simulation Setup for Evaluating AODV}

\section{Protocol}

All the parameters that have to be taken into consideration are given below in the tabular form. The two TCP variant to be used here in this analysis are RENO and NEW RENO.

Table -1: Parameters used in setting up AODV scenario

\begin{tabular}{|l|l|l|}
\hline No of Nodes & 20 & 20 \\
\hline Node speed & $10 \mathrm{~m} / \mathrm{s}$ & $10 \mathrm{~m} / \mathrm{s}$ \\
\hline Pause Time & $200 \mathrm{sec}$ & $200 \mathrm{sec}$ \\
\hline File Size & $\begin{array}{l}50,000 \\
\text { bytes }\end{array}$ & $\begin{array}{l}50,000 \\
\text { bytes }\end{array}$ \\
\hline Area & $1000 \times 1000$ & $1000 \times 1000$ \\
\hline
\end{tabular}




\begin{tabular}{|l|l|l|}
\hline Connection Speed & $11 \mathrm{Mbps}$ & $11 \mathrm{Mbps}$ \\
\hline TCP variant & Reno & New Reno \\
\hline MANET Protocol & AODV & AODV \\
\hline
\end{tabular}

\subsection{Delay, 20 Nodes with Reno}

The below shown is the graph for delay for 20 nodes simulation scenario with TCP variant RENO in square area of $1000 \times 1000$. The connection speed in this case is $11 \mathrm{mb} / \mathrm{sec}$. The mobility is taken in this is $10 \mathrm{~m} / \mathrm{sec}$. The protocol use in this is AODV. The maximum value for the delay is approx 0.0195 sec.

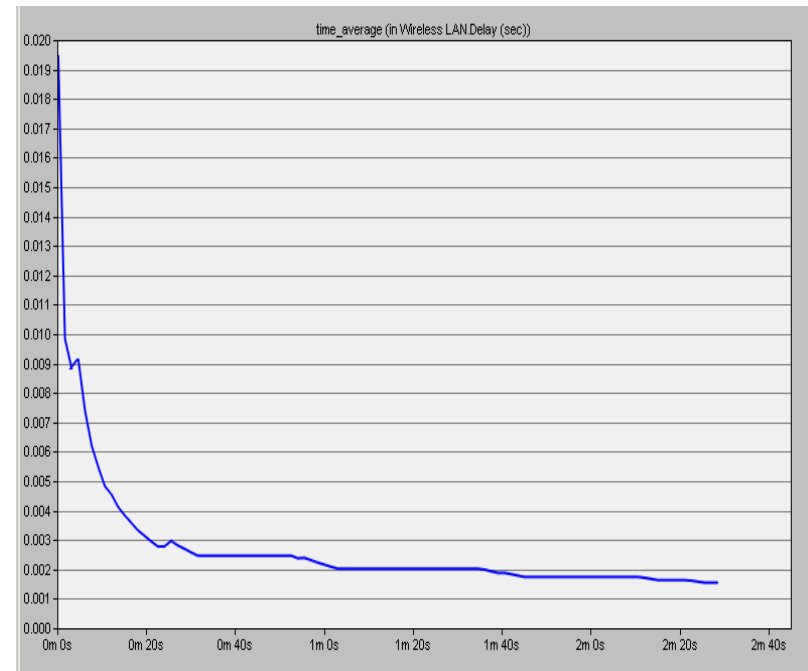

Fig-1: Delay of 20 node network with TCP variant (Reno)

\subsection{Throughput, 20 Nodes with Reno}

The below shown is the graph for throughput for 20 nodes simulation scenario with TCP variant RENO in square area of $1000 \times 1000$. The connection speed in this case is $11 \mathrm{mb} / \mathrm{sec}$. The mobility is taken in this is $10 \mathrm{~m} / \mathrm{sec}$. The protocol use in this is AODV. The maximum value for the throughput is approx $3.58 \times 10^{6} \mathrm{sec}$.

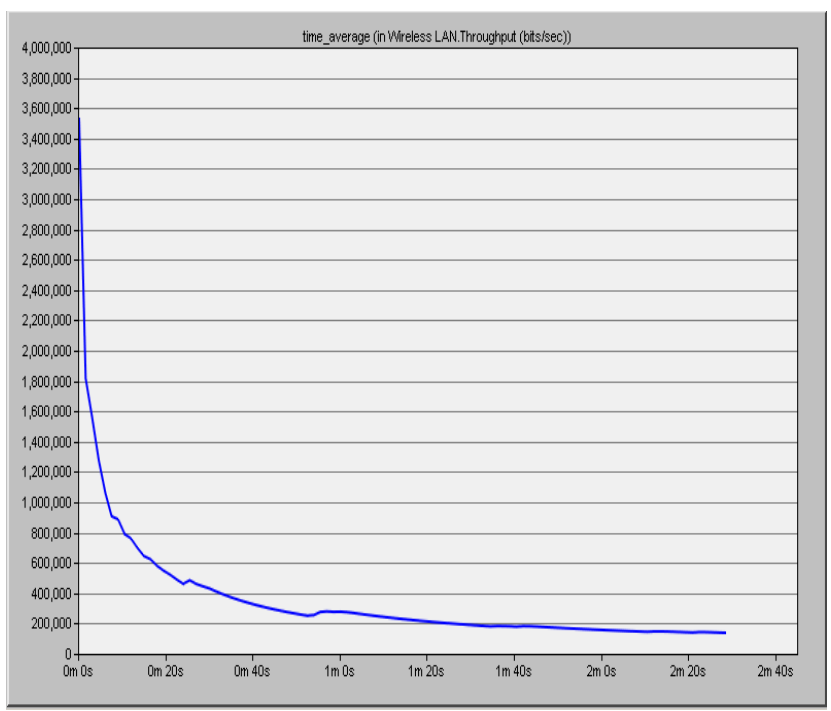

Fig-2: Throughput of 20 node network with TCP variant (Reno)

\subsection{Delay, 20 Nodes with New Reno}

The below shown is the graph for delay for 20 nodes simulation scenario with TCP variant RENO in square area of $1000 \times 1000$. The connection speed in this case is $11 \mathrm{mb} / \mathrm{sec}$. The mobility is taken in this is $10 \mathrm{~m} / \mathrm{sec}$. The protocol use in this is AODV. The maximum value for the delay is approx 0.0225 sec.

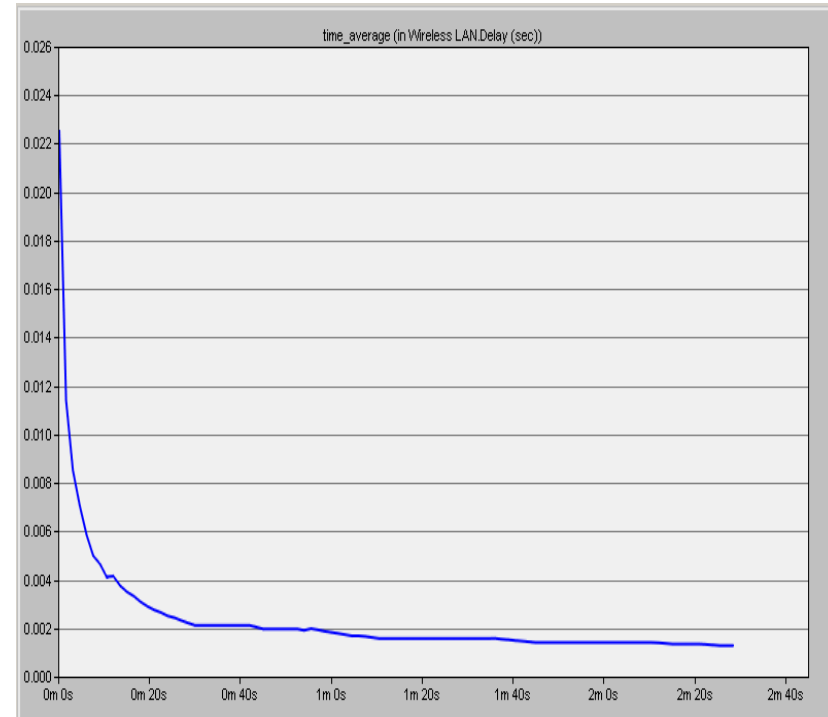

Fig-3: Delay of 20 node network with TCP variant (New Reno)

\subsection{Throughput, 20 Nodes with New Reno}

The below shown is the graph for throughput for 20 nodes simulation scenario with TCP variant NEW RENO in square area of $1000 \times 1000$. The connection speed in this case is $11 \mathrm{mb} / \mathrm{sec}$. The mobility is taken in this is $10 \mathrm{~m} / \mathrm{sec}$. The protocol use in this is AODV. The maximum value for the throughput is approx $4.48 \times 10^{6}$ sec.

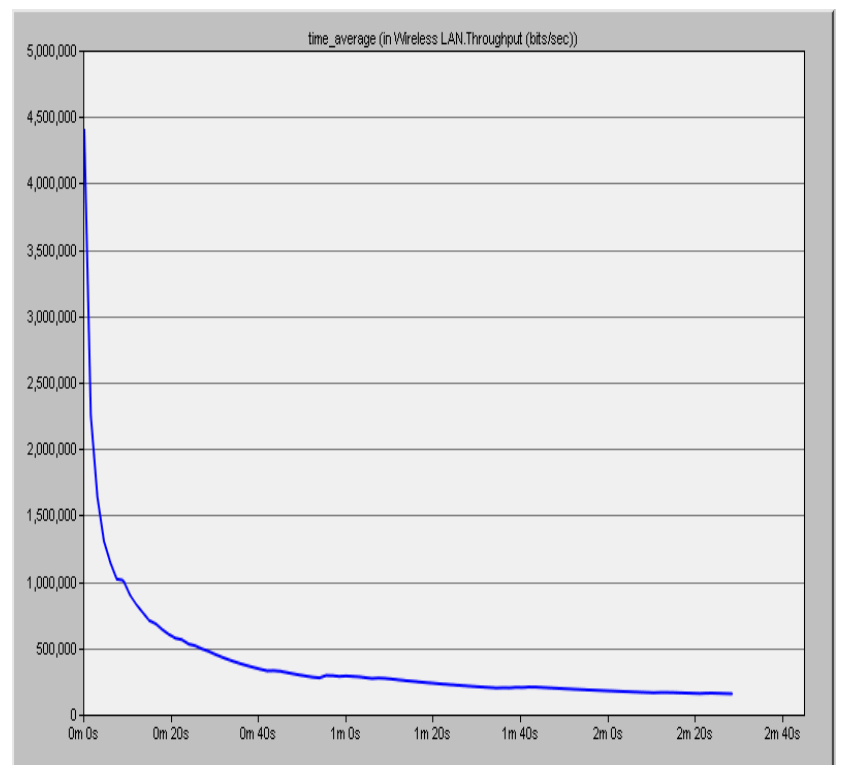

Fig-4: Throughput of 20 node network with TCP variant (New Reno) 


\subsection{Comparisons of Delays and Throughputs}

The below shown is the graphs used to compare the delay and throughput of both Reno and New Reno. The red graph is for Reno with protocol AODV and blue graph is for New Reno.

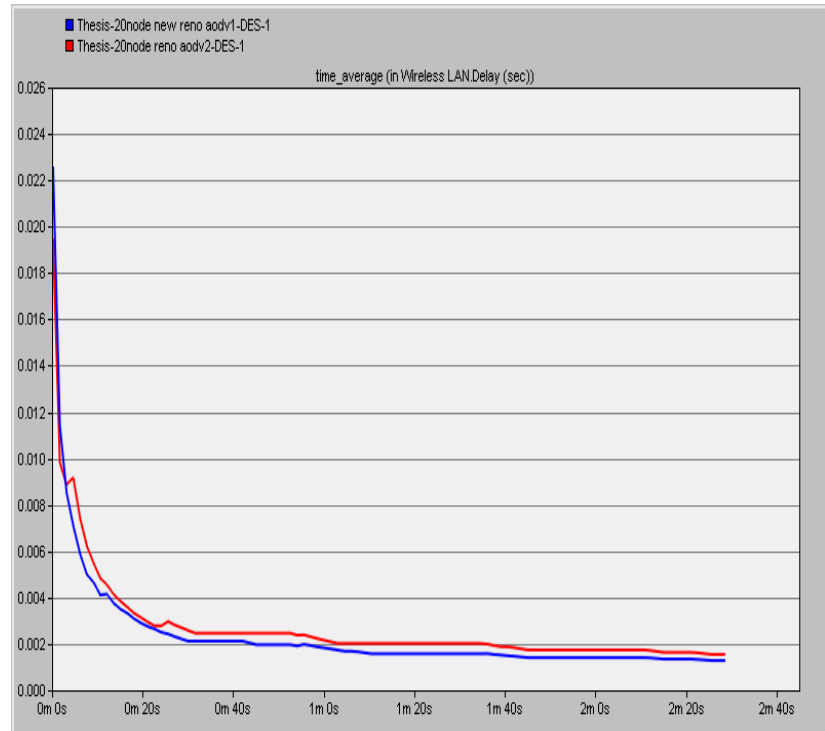

Fig 5 Comparison of the delays of 20 nodes Reno and New Reno

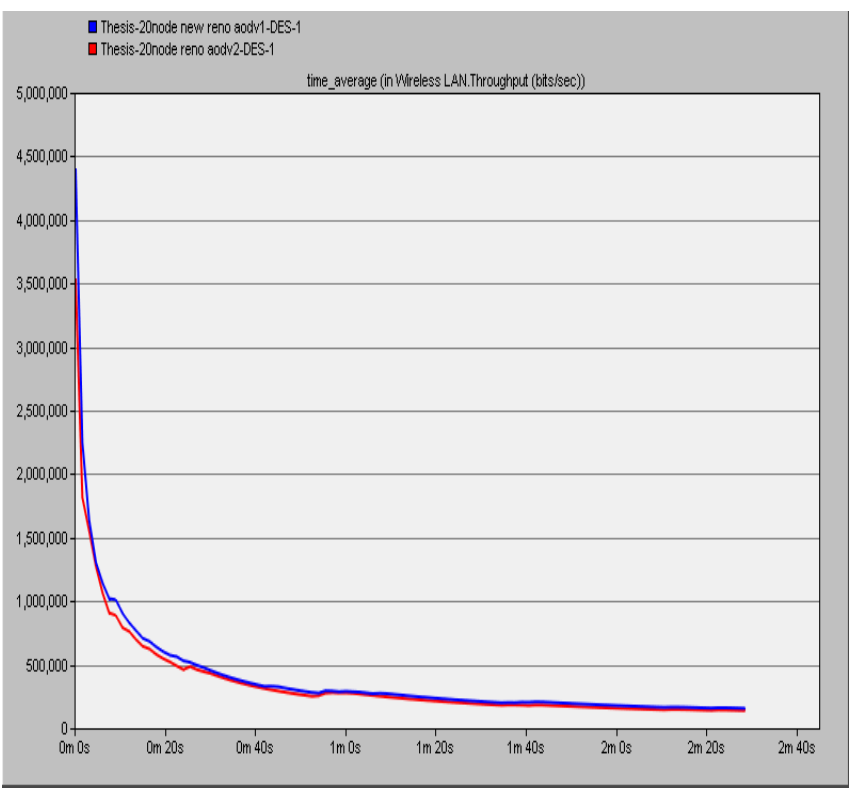

Fig 6 Comparison of the throughputs of 20 nodes Reno and New Reno

Table -2: Comparative Results of RENO and NEW RENO

\begin{tabular}{|l|l|l|}
\hline TCP Variant & RENO & NEW RENO \\
\hline Protocol & AODV & AODV \\
\hline Nodes & 20 & 20 \\
\hline Delay (in sec) & 0.0195 & 0.0225 \\
\hline $\begin{array}{l}\text { Throughput } \\
\text { (Bits/Sec) }\end{array}$ & $3.58 \times 10^{6}$ & $4.48 \times 10^{6}$ \\
\hline
\end{tabular}

\subsection{Simulation Setup for Evaluating OLSR}

\section{Protocol:}

Table -3: Parameters used in setting up scenario for OLSR

\begin{tabular}{|l|l|}
\hline Traffic Type & FTP \\
\hline Protocol & OLSR \\
\hline Mobility Model & Random way point \\
\hline Area & $1000 \times 1000$ \\
\hline Data Rate & $1,2,5.5,11 \mathrm{mbps}$ \\
\hline No of Nodes & 40 \\
\hline
\end{tabular}

\subsection{Delay, Protocol OLSR for Different Data Rates}

The below shown is the delay by taking different data rates with protocol OLSR. Its simulation parameters are shown in table no 3 . In this the blue graph is for data rate $1 \mathrm{mbps}$, the red one is for data rate $2 \mathrm{mbps}$. Similarly the green one is for $5.5 \mathrm{mbps}$ and sky blue is for data rate $11 \mathrm{mbps}$.

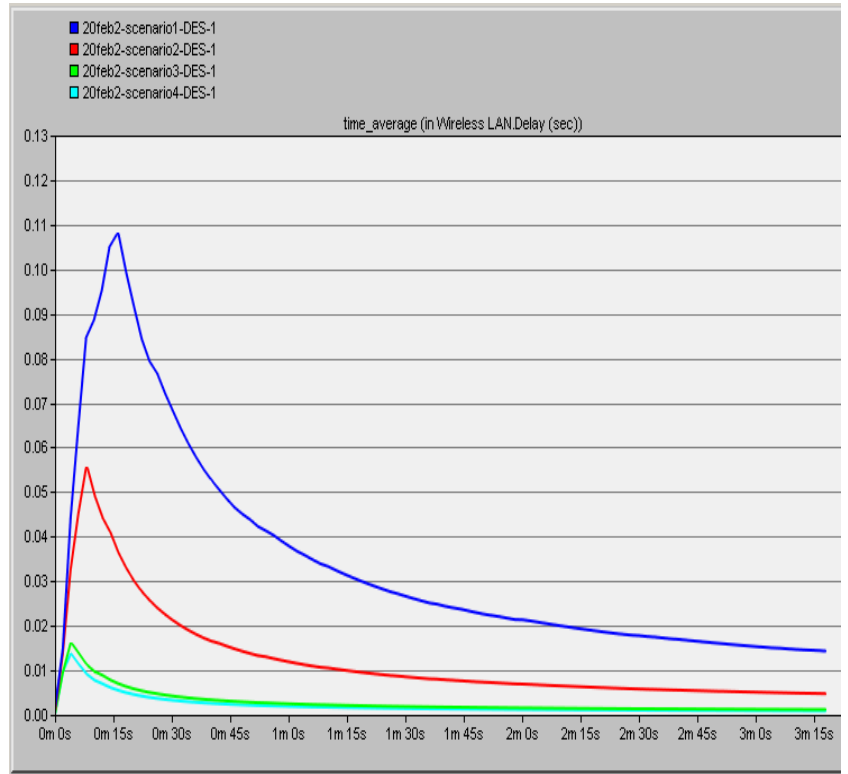

Fig 7 Average end to end delay of OLSR for all Data rates

\subsection{Throughput, Protocol OLSR for Different Data}

\section{Rates}

The below shown is the throughput by taking different data rates with protocol OLSR. Its simulation parameters are shown in table no 3 . In this the blue graph is for data rate $1 \mathrm{mbps}$, the red one is for data rate $2 \mathrm{mbps}$. Similarly the green one is for $5.5 \mathrm{mbps}$ and sky blue is for data rate 11 mbps. 


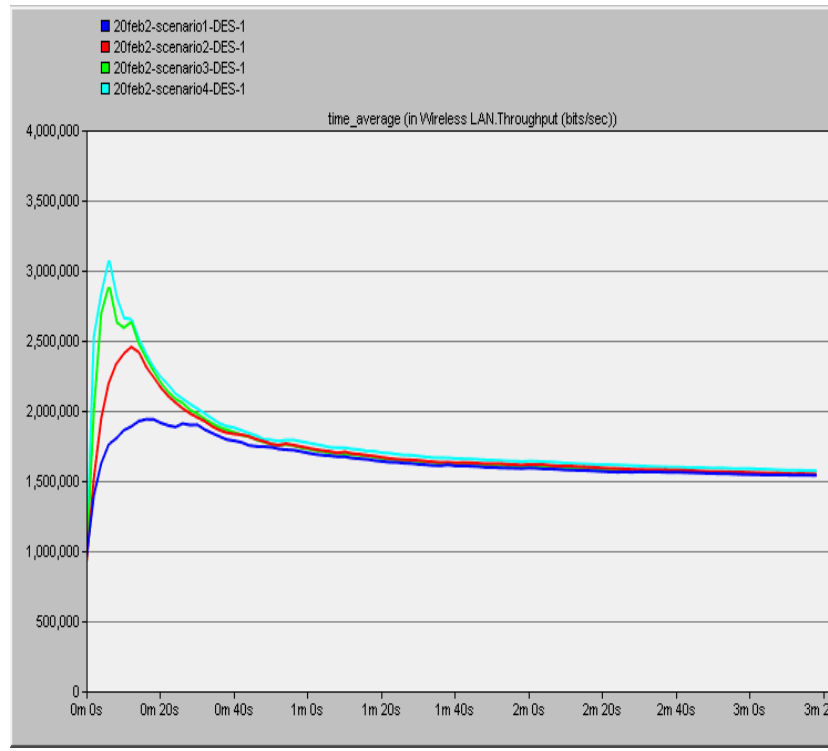

Fig 8 Throughput of OLSR for all Data rates

\subsection{Data Rate Resultant Delay, and Throughput}

Table 4 Resultant data

\begin{tabular}{|l|l|l|l|}
\hline Protocol & $\begin{array}{l}\text { Data Rate } \\
\text { (mbps) }\end{array}$ & $\begin{array}{l}\text { Delay } \\
\text { (sec) }\end{array}$ & $\begin{array}{l}\text { Throughput } \\
\text { (bits/sec) }\end{array}$ \\
\hline OLSR & 1.0 & 0.1080 & $1.94 \times 10^{6}$ \\
\hline OLSR & 2.0 & 0.0560 & $2.47 \times 10^{6}$ \\
\hline OLSR & 5.5 & 0.0163 & $2.88 \times 10^{6}$ \\
\hline OLSR & 1.1 & 0.0137 & $3.17 \times 10^{6}$ \\
\hline
\end{tabular}

\section{CONCLUSIONS}

In the above shown analysis the performance is made between the two different routing protocols i.e AODV and OLSR under different data rates. As we have seen in the simulation we can say that OLSR performs best as compared to the compared to the compared to the AODV routing protocols as the delay will be less in case of OLSR but if we talk about the throughput it is better in case of AODV than OLSR.

\section{REFERENCES}

[1]. Al-Shurman, M., Yoo, S. and Park, S. (2004) "Black hole Attack in Mobile Ad Hoc Networks", ACM Southeast Regional Conference, pp. 96-97, 2004.

[2]. Amjad, K. and Stocker, A.J. (2010) "Impact of node density and mobility on the performance of AODV and DSR in MANETS", CSNDSP 2010.

[3]. D. Triantafyllidou and K. Al Agha. Efficient Adaptation of TCP's RTO Timer to Avoid Spurious Timeouts in MANETs. In WPMC'07

[4]. Demers, S. and Kant, L. (2006) 'MANETs: performance analysis and management', Military Communications Conference,. MILCOM, 23-25 October, Washington, 2006. [5]. Hassan, A. M. , et al. (2006) "Evaluation of Ad Hoc Routing Protocols in Real Simulation Environments" The 2006 International Conference on Computer Engineering and Systems,2006, pp. $288-293$.
[6]. Ilyas, M. (2003) "The Handbook of Ad Hoc Wireless Networks," CRC Press, 2003.

\section{BIOGRAPHIES}

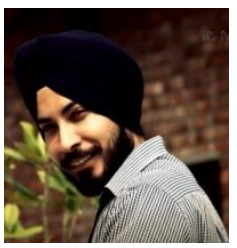

Satinder Singh Minhas, a Lecturer at Lovely Professional University with an experience of 3 years, worked on wireless communication and MANETS

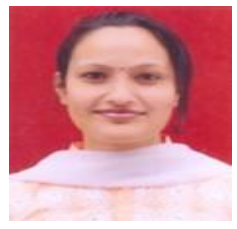

Pooja Chaudhary, Assitant Professor at CTIT with an experience of 9 years, area of interests are computer networks, image processing and cloud computing

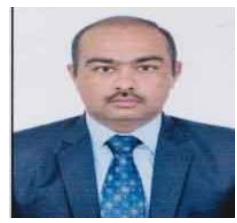

Vikrant Sharma, Vice-Principal at CTIT with an experience of 13.5 years, area of interests are optical communication and microwave engineering.

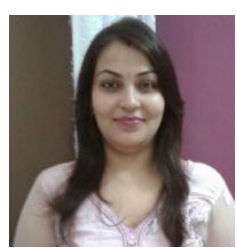

Jaspreet Kaur a Lecturer at Lovely Professional University with an experience of 5 years, worked on wireless communication and optical communication. 